\title{
BMJ Open Postnuclear disaster evacuation and chronic health in adults in Fukushima, Japan: a long-term retrospective analysis
}

\author{
Shuhei Nomura, ${ }^{1}$ Marta Blangiardo, ${ }^{1,2}$ Masaharu Tsubokura, ${ }^{3}$ Akihiko Ozaki, ${ }^{4}$ \\ Tomohiro Morita, ${ }^{5}$ Susan Hodgson ${ }^{1,2}$
}

To cite: Nomura $S$, Blangiardo M, Tsubokura M, et al. Postnuclear disaster evacuation and chronic health in adults in Fukushima, Japan: a long-term retrospective analysis. $B M J$ Open 2016;6: 010080. doi:10.1136/bmjopen-2015010080

- Prepublication history and additional material is available. To view please visit the journal (http://dx.doi.org/ 10.1136/bmjopen-2015010080)

Received 22 September 2015 Revised 11 November 2015 Accepted 2 December 2015

CrossMark

For numbered affiliations see end of article.

Correspondence to

Shuhei Nomura;

s.nomura13@imperial.ac.uk

\section{ABSTRACT}

Objective: Japan's 2011 Fukushima Daiichi Nuclear Power Plant incident required the evacuation of over a million people, creating a large displaced population with potentially increased vulnerability in terms of chronic health conditions. We assessed the long-term impact of evacuation on diabetes, hyperlipidaemia and hypertension.

Participants: We considered participants in annual public health check-ups from 2008 to 2014, administrated by Minamisoma City and Soma City, located about 10-50 km from the Fukushima nuclear plant.

Methods: Disease risks, measured in terms of preincident and post-incident relative risks, were examined and compared between evacuees and non-evacuees/ temporary-evacuees. We also constructed logistic regression models to assess the impact of evacuation on the disease risks adjusted for covariates.

Results: Data from a total of 6406 individuals aged 40-74 years who participated in the check-ups both at baseline (2008-2010) and in one or more postincident years were analysed. Regardless of evacuation, significant post-incident increases in risk were observed for diabetes and hyperlipidaemia (relative risk: $1.27-1.60$ and 1.12-1.30, respectively, depending on evacuation status and post-incident year). After adjustment for covariates, the increase in hyperlipidaemia was significantly greater among evacuees than among non-evacuees/temporaryevacuees (OR 1.18, 95\% $\mathrm{Cl} 1.06$ to $1.32, \mathrm{p}<0.01)$.

Conclusions: The singularity of this study is that evacuation following the Fukushima disaster was found to be associated with a small increase in long-term hyperlipidaemia risk in adults. Our findings help identify discussion points on disaster planning, including preparedness, response and recovery measures, applicable to future disasters requiring mass evacuation.

\section{INTRODUCTION}

Radiation exposure is a public health issue, associated with long-term risks of disorders including, for example, eye cataracts and tumours. Following Japan's Fukushima

\section{Strengths and limitations of this study}

- This is the first study to assess the long-term impact of evacuation on diabetes, hyperlipidaemia and hypertension following Japan's 2011 Fukushima nuclear incident.

- Public health check-up data for 2008-2014 from the most affected areas, $10-50 \mathrm{~km}$ from the Fukushima nuclear power plant, were evaluated.

- Area-level radiation concentrations, a potential confounder for the evacuation effect on chronic health, was taken into account.

- Health check-ups were provided only to the selfemployed and on a voluntary basis, potentially biasing the results and limiting our ability to generalise to the wider population.

Daiichi Nuclear Power Plant incident, triggered by the Great East Japan Earthquake and subsequent tsunami on 11 March 2011, ${ }^{1}$ health threats have arisen in the radiationcontaminated areas, and cumulative dose from external and internal radiation exposure is the major public concern. ${ }^{1-5}$ Contrary to the concern, as Tsubokura et al and Hayano et $a l^{6-15}$ acknowledged in their continuing series of studies and assessments of levels of radiation exposure due to the Fukushima incident, the levels of dose attributed to the incident have been low owing to the weathering process and the success of contaminated food control. The United Nations Scientific Committee on the Effects of Atomic Radiation and the WHO have concluded that the predicted risk of lifetime cancer is very low in the general public, except for the most exposed infants and children in the Fukushima Prefecture, in whom thyroid cancer cases exceeding the norm are estimated by model calculations, although they are difficult to verify in practice due to the low normal rates of thyroid cancer, even a large relative increase represents a small absolute increase in cases. ${ }^{16} 17$ 
Despite the likely low risk of radiation-related health consequences, the health effects of the Fukushima incident are not limited to those due to radiation exposure. A major disaster often requires evacuation of a large population, which exerts a powerful influence on individual vulnerability to psychological stress and creates changes in socioeconomic status (eg, employment and income), thus impacting on people's health. ${ }^{18-21}$ the Fukushima incident is no exception. Soon after the incident, following a series of government evacuation instructions, over 80000 people from the area surrounding the Fukushima nuclear power plant were forced to relocate within the Fukushima Prefecture, or move out of this Prefecture, with some moving hundreds of kilometres away from the plant; some moved several times. ${ }^{22}$ Of those who were made to evacuate, more than 70000 are still subject to a range of evacuation measures as of 5 September 2015, following slight lifts of the instructions. ${ }^{23}$ Yasumura $e t a l^{4}$ and Nomura et $a l^{25}$ reported threefold increase in mortality among evacuated nursing home residents up to 1 year following the incident. Elevated values of metabolic markers, including body mass index (BMI), blood pressure, glucose metabolism, lipid metabolism and liver function, were also demonstrated in evacuees, by Satoh $e t a l^{26}$ and Tsubokura et $a l^{27} 1$ year after the incident, suggesting worsening chronic health conditions. Yabe et $a l^{28}$ showed that, 2 years after the incident, the proportion of adult evacuees who scored above the K6 psychological distress index cut-off point $(\geq 13)$ for general mental health, was four to five times higher than that of the pre-incident general population in Japan.

Understanding the evacuation risk is the basis of disaster risk reduction policy and action, and many studies of past emergency/disaster events have articulated the importance of safe evacuation. ${ }^{29}$ In this context, there is scope to take lessons from our Fukushima experience, not only with respect to radiation protection aspects, but also the impacts of evacuation. Four years after the Fukushima incident, the acute phase (ie, days to months) health impacts of evacuation have been well evaluated, including by the investigation commission appointed by the National Diet of Japan authority. ${ }^{30}$ However, the long-term health consequences, that is, those occurring years after the incident and evacuation, have not been well documented. These long-term impacts are hard to establish because of the scarcity of information on the present health status of affected residents, which is due to expensive research/survey costs and difficulty in tracking individuals over time. ${ }^{31} 32$

In Japan, municipal public health centres provide annual free health check-ups for self-employed residents aged 40-74 years. We evaluated the data from these public health check-ups in the most affected areas of the Fukushima Prefecture in the 4 years following the Fukushima nuclear incident. The research objective of the present study was to assess the impact of evacuation on chronic health. We aimed to (1) gain a stronger understanding of the influence of evacuation on longterm health in order to inform the design and delivery of measures to manage health risks after the Fukushima incident and (2) identify discussion points on disaster planning for future disasters requiring evacuation and/ or involving displaced populations.

\section{METHODS}

\section{Design, settings and participants}

The study sites are Minamisoma City, located in 10 $40 \mathrm{~km}$ from the Fukushima Daiichi Nuclear Power Plant, and Soma City, located to the north of Minamisoma, and $35-50 \mathrm{~km}$ from the Nuclear Power Plant, where we have been supporting clinical care and research since the incident. Note that Japan has three levels of government: national, prefectural and municipal. The nation is divided into 47 prefectures. Each prefecture consists of numerous municipalities, and there are three types of municipalities in Japan: cities, towns and villages. On 12 March 2011, a $20 \mathrm{~km}$ radius from the nuclear plant was denoted by the central government as a restricted area with compulsory evacuation. ${ }^{30}$ Minamisoma therefore straddles the initial compulsory evacuation restriction zone (where about 17000 people had lived, representing $24.7 \%$ of the total population of Minamisoma), ${ }^{33}$ while Soma was entirely outside this zone. The pre-incident populations (as of February 2011) of Minamisoma and Soma were 71494 and 38054 , respectively. ${ }^{33} 34$ On 22 April 2011, the compulsory evacuation zone was expanded slightly to the northwest based on the measured dispersion of highly radioactive fallout (figure 1), and on 16 April 2012, this compulsory evacuation zone was reclassified into three zones in line with air dose rates (figure 1): (1) difficult-to-return zone; (2) no-residence zone and (3) zone being prepared for lifting of the evacuation order. With frequent small changes, these evacuation instructions are still in effect today. The geographical scope of these 2012 instructions and the locations of Minamisoma and Soma, relative to the nuclear power plant, are shown in figure 1 .

We employed data from public health check-ups, administrated by the Minamisoma and Soma city offices, from 2008 to 2014, and compared post-incident data (2011-2014) with pre-incident 'baseline' data (20082010). The public health check-up is available only for those aged 40-74 years, and covered by National Health Insurance, which is designed for people who are not eligible for any employment-based health insurance programmes (ie, the self-employed, such as farmers, fishermen, etc), and is performed annually at the designated community centres and medical institutions during June-October. A health check-up notification is sent to each household every year, based on the city's family registry. The check-up information is also disseminated using each city's public relations magazine. The check-up comprises a physical examination, blood sample test, and self-report medical history and lifestyle 


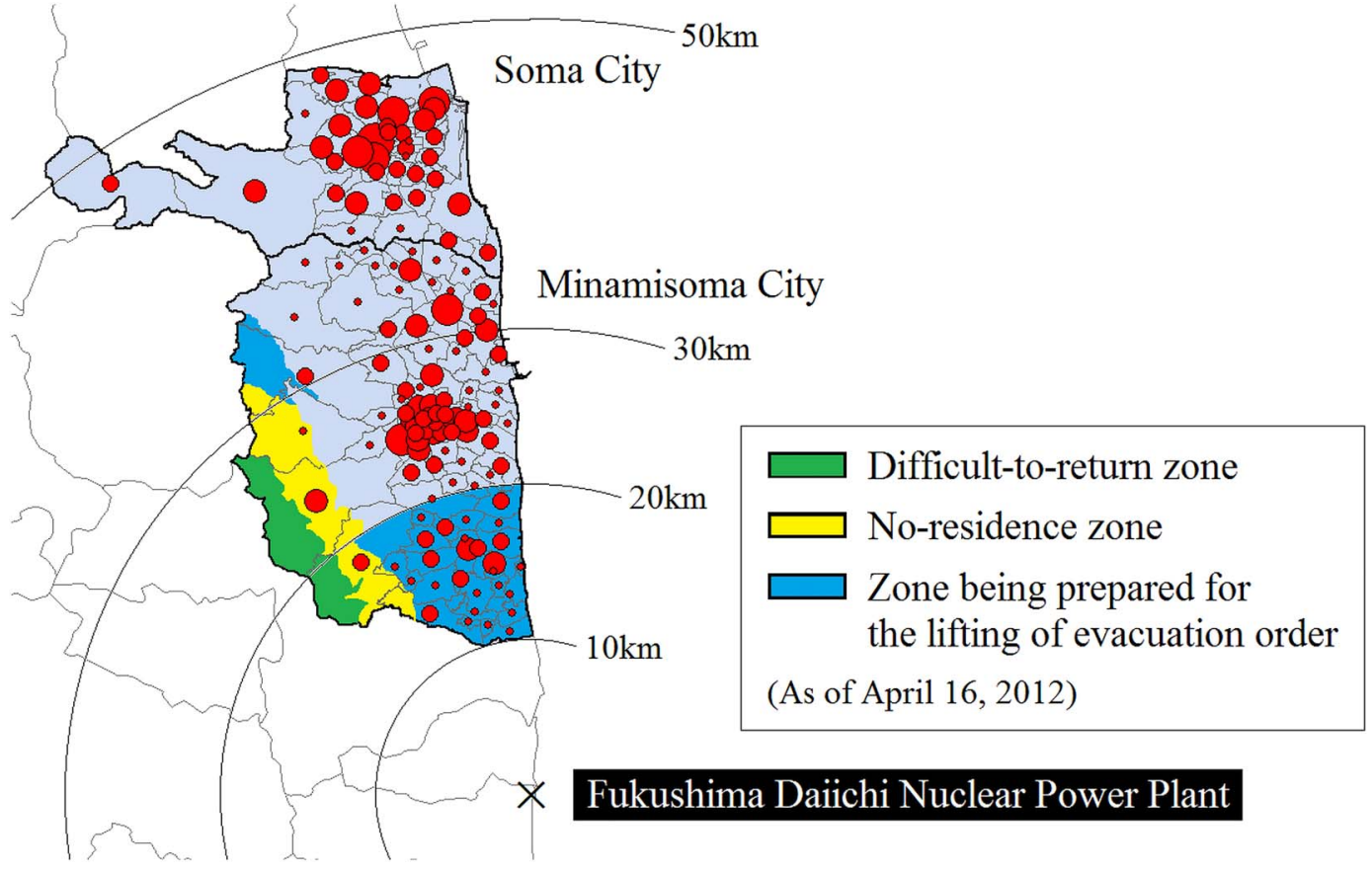

Figure 1 Geographical location of Minamisoma City and Soma City. The red circles show the geographical distribution of the health check-up participants in 2010, where the circles are proportional to the number of participants living in each district. The compulsory evacuation zone is divided into the (1) difficult-to-return zone (in green), where the annual dose of radiation is expected to be $50 \mathrm{mSv}$ or more and people are not allowed to return home until at least March 2017; (2) no-residence zone (in yellow), where the annual dose is expected to be 20-50 mSv and people can temporarily return home to the area, but staying overnight is prohibited and (3) zone being prepared for lifting of the evacuation order (in blue), where the annual dose is expected to be $<20 \mathrm{mSv}$ and people can temporarily return home to the area, but staying overnight is prohibited.

survey. The analysed data set included age and gender; clinical characteristics and blood test results from the physical examination; and family disease history, surgical history, treatment history and lifestyle information from the self-report survey. Details are shown in table 1 and online supplementary table S1. In addition, we considered district-level radiation levels (see below section, 'Air dose rates').

As outcome measures of this study, we considered diabetes, hyperlipidaemia and hypertension. To define each outcome, we used the clinical guidelines for disease diagnosis or self-reported medication use: glycated haemoglobin (HbA1c) of $\geq 6.5 \%$ or use of antihyperglycaemic agents for diabetes; low-density lipoprotein cholesterol (LDL-C) of $\geq 140 \mathrm{mg} / \mathrm{dL}$ or use of antihyperlipidaemic agents for hyperlipidaemia; and systolic blood pressure of $\geq 140 \mathrm{~mm} \mathrm{Hg}$, diastolic blood pressure of $\geq 90 \mathrm{~mm} \mathrm{Hg}$, or use of antihypertensive agents, for hypertension. ${ }^{35-37}$ We considered only those who participated in the check-ups both at baseline and in one or more target years. Note that not every individual had a check-up every year. For individuals who took the check-ups several times in a year, data from the first check-up in the year were considered.

\section{Air dose rates}

Data were collected from the official website of Ministry of Education, Culture, Sports, Science, and Technology $(\mathrm{MEXT})$. After the nuclear incident, MEXT has irregularly conducted airborne monitoring within an $80 \mathrm{~km}$ radius of the nuclear power plant. The monitoring is performed at $300 \mathrm{~m}$ above the ground and the track width is about $1.85 \mathrm{~km}$. The recorded value is the average of the measured values within circles with a diameter of approximately $600 \mathrm{~m}$ at ground level. The data contain the air dose rates $(\mu \mathrm{Sv} / \mathrm{h})$ at a height of $1 \mathrm{~m}$ above the ground measured in terms of the ambient dose equivalent $\left(\mathrm{H}^{*} 10\right),{ }^{38}$ which includes the natural radiation background from the earth's crust, such as from rocks and soil; and the latitude and longitude coordinates of their monitoring points. All monitored results are open to the public and available online. ${ }^{39}$

We considered the results of the third MEXT monitoring performed between 31 May and 2 July 2011; fifth monitoring between 22 and 28 June 2012; seventh monitoring between 27 August to 28 September 2013; and ninth between 1 September and 7 November 2014, for the radiation levels of 2011, 2012, 2013 and 2014, respectively. ${ }^{39}$ The district-level radiation level was then calculated by averaging the values at each monitoring point within a district by year, and this district average value was then assigned to each participant in each year, based on district of residence at baseline.

\section{Data analysis}

Subgroup classification

We classified the participants into two subgroups by evacuation status: evacuees and non-evacuees/ temporary-evacuees. Based on the pre-incident 
Table 1 Comparisons of subject characteristics between evacuees and non-evacuees/temporary-evacuees

\begin{tabular}{|c|c|c|c|c|c|c|c|c|c|c|}
\hline & \multicolumn{2}{|c|}{ Baseline (2008-2010) } & \multicolumn{2}{|l|}{2011} & \multicolumn{2}{|l|}{2012} & \multicolumn{2}{|l|}{2013} & \multicolumn{2}{|l|}{2014} \\
\hline & Evacuees & $\begin{array}{l}\text { Non-evacuees/ } \\
\text { temporary- } \\
\text { evacuees }\end{array}$ & Evacuees & $\begin{array}{l}\text { Non-evacuees/ } \\
\text { temporary- } \\
\text { evacuees }\end{array}$ & Evacuees & $\begin{array}{l}\text { Non-evacuees/ } \\
\text { temporary- } \\
\text { evacuees }\end{array}$ & Evacuees & $\begin{array}{l}\text { Non-evacuees/ } \\
\text { temporary- } \\
\text { evacuees }\end{array}$ & Evacuees & $\begin{array}{l}\text { Non-evacuees/ } \\
\text { temporary- } \\
\text { evacuees }\end{array}$ \\
\hline \multicolumn{11}{|l|}{ City of residence $(\mathrm{N})$} \\
\hline Minamisoma & 960 & 2818 & 216 & 832 & 627 & 1925 & 657 & 2055 & 617 & 1990 \\
\hline Soma & 0 & 2628 & 0 & 2038 & 0 & 1961 & 0 & 1625 & 0 & 1601 \\
\hline Total & 960 & 5446 & 216 & 2870 & 627 & 3886 & 657 & 3680 & 617 & 3591 \\
\hline \multicolumn{11}{|l|}{ Demographic characteristics } \\
\hline Age in years (mean, SD) & $62.0(6.6)$ & $62.4(7.1)$ & $64.9(6.3)$ & $64.8(7.3)$ & $65.3(6.4)$ & $65.3(6.9)$ & $65.5(6.5)$ & $65.7(6.6)$ & $66.0(6.3)$ & $66.3(6.3)$ \\
\hline \multicolumn{11}{|l|}{ Gender (N, \%) } \\
\hline Male & $404(41.9)$ & $2203(40.5)$ & $95(44.0)$ & $1169(40.7)$ & 267 (42.6) & $1578(40.6)$ & $281(42.8)$ & $1459(39.7)$ & $254(41.2)$ & $1375(38.3)$ \\
\hline Female & $556(58.1)$ & $3243(59.5)$ & $121(56.0)$ & $1701(59.3)$ & $360(57.4)$ & $2308(59.4)$ & $376(57.2)$ & $2221(60.4)$ & $363(58.8)$ & $2216(61.7)$ \\
\hline \multicolumn{11}{|c|}{ Clinical characteristics (mean, SD) } \\
\hline BMI $\left(\mathrm{kg} / \mathrm{m}^{2}\right)$ & $23.6(3.2)$ & $23.5(3.3)$ & $24.0(3.4)$ & $23.6(3.3)$ & $24.2(3.3)^{\star \star \star}$ & $23.6(3.4)^{\star \star \star}$ & $24.0(3.3)^{\star *}$ & $23.6(3.4)^{\star \star}$ & $23.7(3.4)^{\star}$ & $23.4(3.4)^{\star}$ \\
\hline $\begin{array}{l}\text { Systolic blood pressure } \\
(\mathrm{mm} \mathrm{Hg})\end{array}$ & $130.5(16.1)$ & $130.7(16.3)$ & $130.0(14.6)$ & $131.7(16.0)$ & $128.9(15.5)^{\star}$ & $130.7(16.2)^{\star}$ & $128.0(14.6)$ & $128.7(15.2)$ & $126.5(14.1)^{\star \star}$ & $128.4(14.8)^{\star *}$ \\
\hline $\begin{array}{l}\text { Diastolic blood pressure } \\
(\mathrm{mm} \mathrm{Hg})\end{array}$ & $77.5(9.5)$ & $77.5(9.7)$ & $78.0(11.3)$ & $79.0(10.2)$ & $76.7(10.2)$ & $76.9(10.3)$ & $76.3(9.2)$ & $75.7(9.8)$ & $74.6(9.3)$ & $75.1(9.6)$ \\
\hline $\mathrm{HbA1c}(\%)$ & $5.5(0.6)$ & $5.5(0.6)$ & $5.4(0.5)$ & $5.5(0.6)$ & $5.6(0.5)$ & $5.6(0.6)$ & $5.7(0.6)$ & $5.7(0.6)$ & $5.6(0.6)$ & $5.6(0.6)$ \\
\hline HDL-C (mg/dL) & $61.4(14.4)$ & $61.4(14.8)$ & $59.8(14.5)$ & $60.9(14.7)$ & $56.2(13.2)^{\star \star \star}$ & $58.8(14.3)^{\star \star \star}$ & $57.9(13.9)^{\star \star}$ & $59.6(14.3)^{\star \star}$ & $58.1(13.8)^{\star \star \star}$ & $60.3(14.8)^{\star \star \star}$ \\
\hline LDL-C (mg/dL) & $124.9(30.0)$ & $125.4(31.0)$ & $126.5(30.9)$ & 124.4 (31.1) & $120.0(31.1)$ & $122.2(31.0)$ & $123.5(30.5)$ & $124.8(31.0)$ & $121.0(29.7)^{\star *}$ & $124.8(31.2)^{\star *}$ \\
\hline ALT/GPT (IU/L) & 22.0 & 22.7 (18.5) & $23.3(16.5)$ & 24.7 (17.7) & $24.2(16.4)$ & 23.4 (18.2) & $23.0(16.6)$ & 22.1 (19.3) & $22.8(16.4)$ & 22.1 (14.6) \\
\hline AST/GOT (IU/L) & $24.8(11.5)$ & 25.1 (11.9) & $24.8(8.7)$ & $26.4(15.0)$ & 26.4 (13.9) & 25.7 (12.2) & 25.1 (12.2) & $24.9(15.6)$ & 24.6 (10.9) & $24.8(14.7)$ \\
\hline$\gamma$-GTP (IU/L) & $34.0(40.9)$ & $37.4(51.4)$ & $35.8(42.4)$ & $39.3(56.7)$ & $38.6(43.8)$ & 36.6 (44.9) & 36.8 (51.2) & $36.4(56.4)$ & 34.5 (63.7) & $35.8(55.2)$ \\
\hline $\begin{array}{l}\text { Urine protein } \\
\text { ( } \mathrm{N}, \% \text { of positive) }\end{array}$ & $16(1.7)$ & $115(2.1)$ & $3(1.4)$ & $58(2.0)$ & $6(1.0)$ & $64(1.7)$ & $13(2.0)$ & $59(1.6)$ & $8(1.3)$ & $68(1.9)$ \\
\hline $\begin{array}{l}\text { Urine occult blood } \\
\text { (N, \% of positive) }\end{array}$ & $55(5.7)$ & $319(5.9)$ & $20(9.3)$ & $209(7.6)$ & $17(2.7)^{\star}$ & $184(4.8)^{\star}$ & $30(4.6)$ & $185(5.1)$ & $30(4.9)$ & $163(4.6)$ \\
\hline $\begin{array}{l}\text { Urine glucose } \\
\text { ( } \mathrm{N}, \% \text { of positive) }\end{array}$ & $19(2.0)$ & $130(2.4)$ & $2(0.9)$ & $60(2.1)$ & $8(1.3)$ & $89(2.3)$ & $10(1.5)$ & $74(2.0)$ & $14(2.3)$ & $68(1.9)$ \\
\hline \multicolumn{11}{|c|}{ Medical characteristics of interests $(\mathrm{N}, \%)$} \\
\hline \multicolumn{11}{|c|}{ Presence of diseases } \\
\hline Diabetes & $74(7.7)$ & $415(7.7)$ & $20(9.3)$ & $226(8.0)$ & 64 (10.2) & $368(9.5)$ & $86(13.1)$ & $423(11.6)$ & $84(13.6)$ & $399(11.2)$ \\
\hline Hyperlipidaemia & $430(44.8)$ & $2390(44.3)$ & $109(50.5)$ & $1290(45.2)$ & $336(53.6)^{\star \star}$ & $1815(46.8)^{\star *}$ & $394(60.0)^{\star \star *}$ & $1877(51.2)^{\star \star \star}$ & $341(55.3)$ & $1874(52.6)$ \\
\hline Hypertension & $437(45.5)$ & $2463(45.3)$ & $112(51.9)$ & $1506(52.6)$ & $333(53.1)$ & $2020(52.1)$ & $366(55.7)^{\star}$ & $1888(51.3)^{\star}$ & $297(48.1)$ & $1758(49.2)$ \\
\hline
\end{tabular}


district-level address, those who were living in the districts denoted compulsory evacuation after the incident (ie, all the evacuation areas highlighted in figure 1) were defined as evacuees. Participants who were living outside the compulsory evacuation zones were defined as non-evacuees/temporary-evacuees (including voluntary temporary evacuees). Note that because evacuees usually do not declare their change of address to the city office after their evacuations, the address recorded in the city resident registers collected from the postincident health check-ups indicated not the evacuation site, but pre-incident dwelling site. This means that post-incident addresses of the evacuees were not identified.

\section{Comparison of clinical characteristics between evacuees and non-evacuees/temporary-evacuees}

To examine the impact of evacuation on chronic health, we compared clinical characteristics between evacuees and non-evacuees/temporary-evacuees by year. In addition, the pre-incident and post-incident relative risk (RR) of diabetes, hyperlipidaemia and hypertension were calculated with adjustment for age by evacuation status and year, in order to compare change of the disease prevalence after the incident, between evacuees and non-evacuees/temporary-evacuees. Baseline risk was defined as the average disease prevalence from 2008 to 2010. If an individual took a health check-up more than once in these 3 years, their most recent data were used in calculating the baseline.

\section{Regression analysis}

We conducted regression analyses to assess the impact of evacuation, adjusted for covariates. The regression models were constructed separately for diabetes, hyperlipidaemia and hypertension, using post-incident data (2012-2014). Note that because the health check-up of 2011 was performed only months after the incident, many unobserved factors (eg, environmental/socioeconomic factors) that potentially influence disease risk might exist in 2011 data, and/or variables included in the regression models might have different functions in 2011 than in other years. Hence, to prevent possible bias on regression coefficients, we excluded 2011 from the analysis. Since every participant had more than two check-ups during the study periods, the regression models included a random effect at individual level to control for the fact that the same individual's data were correlated.

We compared disease risk in evacuees versus non-evacuees/temporary-evacuees, using logistic regression. The radiation level at the residential areas may be a significant factor confounding the evacuation effect because it may have strong relationship with psychological stress/anxiety, known to be associated with chronic health conditions. ${ }^{40}{ }^{41}$ However, because the post-incident addresses of the evacuees were not identified, it was impossible to adjust for post-evacuation radiation level. Therefore, to better understand the effect of radiation levels on disease risk, we modelled the associations between the disease risks and radiation levels in non-evacuees/temporary-evacuees. Note that in this analysis, we included district as a random effect to take into account geographical similarities/differences in the response values for the regressions.

Variables initially entered into the regression models were chosen based on the univariate analyses. Additional model selection was performed using backward-stepwise method with p-to-remove of $>0.05 .{ }^{42}$ Backward-stepwise regression starts with all the candidate variables in the model and removes the least significant variables until all the remaining variables are statistically significant. The partial F-test was used to verify for the entry and removal of variables from the model. Variables that were known or suspected risk factors (eg, family history) were incorporated into the final model regardless of their statistical significance.

Geospatial processing of data was conducted using ArcGIS V.10.2 and all statistical analyses were performed using STATA/MP V.13.

\section{RESULTS}

\section{Characteristics of study participants}

A total of 11279 individuals participated in the check-ups between 2011 and 2014. After excluding those who did not take a check-up before the incident $(n=4873)$, we were left with 6406 individuals with pre-incident and postincident data. There was a significant difference in gender distribution between included and excluded individuals $(59.3 \%$ vs $55.6 \%$ female, $\mathrm{p}<0.001)$. The included individuals were more likely to have hypertension in 2011, 2012 and 2013, than excluded individuals (52.5\% vs $46.1 \%$ in $2011, \mathrm{p}<0.01 ; 52.2 \%$ vs $46.8 \%$ in 2012 , $\mathrm{p}<0.001 ; 52.0 \%$ vs $49.0 \%$ in $2013, \mathrm{p}<0.05)$, while postincident prevalence of diabetes and hyperlipidaemia did not differ between excluded and included individuals.

\section{Comparison of clinical characteristics between evacuees and non-evacuees/temporary-evacuees}

Demographic and clinical characteristics are shown in table 1 by evacuation status. Variables did not differ between evacuees and non-evacuees/temporary-evacuees at baseline, nor did they differ in 2011. However, in 2012 to 2014, BMI and high-density lipoprotein cholesterol (HDL-C) were significantly higher and lower, respectively, in evacuees than in non-evacuees/temporary-evacuees. Differences in self-report medical history and lifestyle survey by evacuation status are shown in online supplementary table S1. Although there were no significant differences between evacuees and non-evacuees/ temporary-evacuees in treatment history at baseline and in 2011, a significant difference was identified in treatment for hyperlipidaemia after 2012, with evacuees significantly more likely to receive outpatient treatment than were non-evacuees/temporary-evacuees. In addition, differences in lifestyles between evacuees and non-evacuees/ 
temporary-evacuees were noted. From 2011, evacuees were significantly more likely to have gained or lost more than $3 \mathrm{~kg}$ of their weight over the previous year. From 2012, evacuees were also less likely to feel refreshed after a night's sleep. In addition, the non-evacuees/ temporary-evacuees tended to walk faster than evacuees, both after 2011 and in the baseline year, possibly indicating that the higher BMI after 2012 in evacuees could be somewhat confounded by this walk speed difference.

\section{Age-adjusted RR of diabetes, hypertension and hyperlipidaemia}

Table 2 shows the age-adjusted pre-incident and postincident RR of each outcome. For diabetes, evacuees and non-evacuees/temporary-evacuees both had significantly higher risk in 2013 and 2014 than at baseline. These RRs did not significantly differ between evacuees and non-evacuees/temporary-evacuees in any year. For hyperlipidaemia, in evacuees, risk was significantly higher in 2012, 2013 and 2014, compared to at baseline. In non-evacuees/temporary-evacuees, risks were significantly higher in 2013 and 2014. The RR of hyperlipidaemia by evacuation status was significantly different in $2012(p<0.05)$ and in $2013(p<0.01)$, showing the increased risk in hyperlipidaemia was significantly greater among evacuees than among non-evacuees/ temporary-evacuees. For hypertension, the RR was borderline significant in 2013 for evacuees, and significantly reduced in 2014 for non-evacuees/temporary-evacuees. The difference of the RR of hypertension between evacuees and non-evacuees/temporary-evacuees was not significant in any year.

\section{Regression analyses}

Impact of evacuation after adjustment for covariates

The estimated impact of evacuation on disease risk is shown in table 3 . For diabetes, there was no significant difference in risk between evacuees and non-evacuees/ temporary-evacuees post-incident after adjustment for covariates. We identified a small but significant effect of evacuation on hyperlipidaemia risk (OR 1.18, 95\% CI 1.06 to $1.32, \mathrm{p}<0.01)$. This result is consistent with that shown in table 2, suggesting that the evacuation effect on hyperlipidaemia risk was not entirely accounted for by potentially confounding covariates. In other words, the evacuation effect persisted after adjustment for potential confounders. An interaction term of 'evacuation' and 'year' variables was examined in the regression model to test for the different evacuation impacts by year, but no interaction was observed (data not shown), suggesting that effect of evacuation was similar in 2012, 2013 and 2014. For hypertension and diabetes, no significant difference in risk between evacuees and non-evacuees/temporary-evacuees was identified.

In addition to evacuation, we identified several other covariates associated with disease risk (table 3). For example, the older age group (65-74 years) was significantly more likely to experience an increase in disease risks postincident than the younger age group (40-64 years). Females had twice the risk of hyperlipidaemia as males, while the post-incident risks of diabetes and hypertension were higher in males than in females by about 2 and 1.5 times, respectively. As many previous studies have acknowledged ${ }^{43-45}$ family history of disease was significantly highly associated with disease risk for each outcome. Tobacco use and alcohol consumption were also found to be associated with disease risks, although not always in the expected direction, making these results difficult to interpret. Interestingly, hypertension was significantly associated with eating speed; those with slow eating speed were less likely to have hypertension (OR $0.72,95 \%$ CI 0.63 to 0.84 , $\mathrm{p}<0.001)$.

Impact of radiation level as a proxy of stress/anxiety level Figure 2 shows the distribution of district-level radiation concentrations for non-evacuees/temporary-evacuees by

Table 2 Age-adjusted pre-incident and post-incident relative risk of the diseases (versus baseline (2008-2010))

\begin{tabular}{|c|c|c|c|}
\hline & Evacuees & $\begin{array}{l}\text { Non-evacuees/ } \\
\text { temporary-evacuees }\end{array}$ & $\begin{array}{l}\text { p Value of the } \\
\text { difference in row }\end{array}$ \\
\hline \multicolumn{4}{|c|}{ Diabetes } \\
\hline 2011 & $1.12(0.70$ to 1.79$)$ & $0.94(0.81$ to 1.10$)$ & 0.5 \\
\hline 2012 & 1.21 (0.88 to 1.67$)$ & $1.11(0.97$ to 1.27$)$ & 0.6 \\
\hline 2013 & $1.55(1.15 \text { to } 2.09)^{\star \star}$ & $1.33(1.17 \text { to } 1.52)^{\star \star \star}$ & 0.3 \\
\hline 2014 & $1.60(1.18 \text { to } 2.16)^{\star \star}$ & $1.27(1.11 \text { to } 1.45)^{\star \star \star}$ & 0.1 \\
\hline \multicolumn{4}{|c|}{ Hyperlipidaemia } \\
\hline 2011 & $1.10(0.94$ to 1.27$)$ & $1.00(0.95$ to 1.05$)$ & 0.3 \\
\hline 2012 & $1.16(1.05 \text { to } 1.29)^{\star *}$ & 1.03 (0.98 to 1.08$)$ & $<0.05$ \\
\hline 2013 & $1.30(1.18 \text { to } 1.43)^{\star \star \star}$ & $1.12(1.07 \text { to } 1.17)^{\star \star \star}$ & $<0.01$ \\
\hline 2014 & $1.20(1.08 \text { to } 1.32)^{\star *}$ & $1.14(1.09 \text { to } 1.20)^{\star \star}$ & 0.6 \\
\hline \multicolumn{4}{|c|}{ Hypertension } \\
\hline 2011 & $1.05(0.91$ to 1.21$)$ & 1.05 (1.01 to 1.10$)$ & 1.0 \\
\hline 2012 & $1.04(0.94$ to 1.14$)$ & $1.03(0.99$ to 1.07$)$ & 1.0 \\
\hline 2013 & $1.10(1.00 \text { to } 1.21)^{*}$ & 1.01 (0.97 to 1.05$)$ & 0.1 \\
\hline 2014 & 0.94 (0.85 to 1.05$)$ & $0.95(0.91 \text { to } 0.99)^{*}$ & 0.8 \\
\hline
\end{tabular}


Table 3 Random-effects regression model: OR $(95 \% \mathrm{Cl})$

\begin{tabular}{|c|c|c|c|}
\hline Variable & Diabetes† & Hyperlipidaemiał & Hypertension§ \\
\hline \multicolumn{4}{|l|}{ Demographic characteristics } \\
\hline \multicolumn{4}{|l|}{ Evacuation status } \\
\hline Non-evacuees/temporary-evacuees & 1.00 & 1.00 & 1.00 \\
\hline Evacuees & $1.14(0.96$ to 1.35$)$ & $1.18(1.06 \text { to } 1.32)^{\star \star}$ & $0.97(0.86$ to 1.09$)$ \\
\hline \multicolumn{4}{|l|}{ Year } \\
\hline 2012 & 1.00 & 1.00 & 1.00 \\
\hline 2013 & $1.27(1.10 \text { to } 1.47)^{\star \star}$ & 1.09 (0.99 to 1.19$)$ & $0.95(0.86$ to 1.04$)$ \\
\hline 2014 & $1.23(1.06 \text { to } 1.43)^{\star \star}$ & $1.19(1.08 \text { to } 1.30)^{\star \star \star}$ & $0.80(0.73 \text { to } 0.88)^{\star * *}$ \\
\hline \multicolumn{4}{|l|}{ City } \\
\hline Minamisoma & 1.00 & 1.00 & 1.00 \\
\hline Soma & 1.08 (0.95 to 1.23$)$ & $0.86(0.79 \text { to } 0.93)^{\star \star \star}$ & 1.00 (0.92 to 1.09$)$ \\
\hline \multicolumn{4}{|l|}{ Age in years } \\
\hline$(40-65)$ & 1.00 & 1.00 & 1.00 \\
\hline$(65-74)$ & $1.29(1.12 \text { to } 1.48)^{\star \star \star}$ & $1.13(1.04 \text { to } 1.22)^{\star \star}$ & $2.47(2.27 \text { to } 2.69)^{\star \star \star}$ \\
\hline \multicolumn{4}{|l|}{ Gender } \\
\hline Male & 1.00 & 1.00 & 1.00 \\
\hline Female & $0.43(0.37 \text { to } 0.49)^{\star \star \star}$ & $1.91(1.75 \text { to } 2.10)^{\star \star \star}$ & $0.71(0.65 \text { to } 0.79)^{\star \star \star}$ \\
\hline \multicolumn{4}{|l|}{ Clinical characteristics } \\
\hline $\mathrm{BMI}$ & $1.13(1.11 \text { to } 1.15)^{\star \star \star}$ & $1.07(1.06 \text { to } 1.09)^{\star \star \star}$ & $1.18(1.17 \text { to } 1.2)^{\star \star \star}$ \\
\hline HbA1c (\%) & - & $1.61(1.48 \text { to } 1.75)^{\star \star \star}$ & - \\
\hline$\gamma$-GTP (IU/L) & - & - & $1.00(1.00 \text { to } 1.00)^{\star \star \star}$ \\
\hline \multicolumn{4}{|l|}{ Urine protein } \\
\hline Negative/trace & 1.00 & - & 1.00 \\
\hline Positive & $2.96(2.16 \text { to } 4.05)^{\star \star \star}$ & - & $2.21(1.56 \text { to } 3.13)^{\star \star \star}$ \\
\hline \multicolumn{4}{|l|}{ Medical records } \\
\hline \multicolumn{4}{|l|}{ Use of medicines } \\
\hline \multicolumn{4}{|l|}{ Diabetes } \\
\hline No & - & 1.00 & 1.00 \\
\hline Yes & - & $0.91(0.77$ to 1.07$)$ & $1.45(1.24 \text { to } 1.69)^{\star \star \star}$ \\
\hline \multicolumn{4}{|l|}{ Hyperlipidaemia } \\
\hline No & 1.00 & - & 1.00 \\
\hline Yes & $2.15(1.89 \text { to } 2.45)^{\star \star \star}$ & - & $1.49(1.36 \text { to } 1.63)^{\star \star \star}$ \\
\hline \multicolumn{4}{|l|}{ Hypertension } \\
\hline No & 1.00 & 1.00 & - \\
\hline Yes & $1.49(1.31 \text { to } 1.69)^{\star \star \star}$ & 1.07 (0.99 to 1.16$)$ & - \\
\hline \multicolumn{4}{|l|}{ Family disease history } \\
\hline No & 1.00 & 1.00 & 1.00 \\
\hline Yes & $3.49(3.08 \text { to } 3.96)^{\star \star \star}$ & $4.45(3.35 \text { to } 5.89)^{\star \star \star}$ & $3.12(2.87 \text { to } 3.38)^{\star \star \star}$ \\
\hline \multicolumn{4}{|l|}{ Lifestyle } \\
\hline \multicolumn{4}{|l|}{ Tobacco use } \\
\hline No & 1.00 & 1.00 & 1.00 \\
\hline Yes & $1.26(1.06 \text { to } 1.51)^{*}$ & $0.95(0.84$ to 1.08$)$ & $0.74(0.65 \text { to } 0.84)^{\star \star \star}$ \\
\hline \multicolumn{4}{|l|}{ Alcohol consumption } \\
\hline None/rarely & 1.00 & 1.00 & 1.00 \\
\hline Sometimes & $0.81(0.69 \text { to } 0.96)^{*}$ & $0.94(0.85$ to 1.03$)$ & $1.09(0.99$ to 1.21$)$ \\
\hline Every day & $0.68(0.57 \text { to } 0.80)^{\star \star \star}$ & $0.56(0.50 \text { to } 0.62)^{\star \star \star}$ & $1.72(1.53 \text { to } 1.94)^{\star \star \star}$ \\
\hline \multicolumn{4}{|l|}{ Low intensity exercise (Q3)ף } \\
\hline No & 1.00 & - & - \\
\hline Yes & $1.27(1.12 \text { to } 1.43)^{\star \star \star}$ & - & - \\
\hline \multicolumn{4}{|l|}{ Eating speed (Q10)†† } \\
\hline Normal & - & - & 1.00 \\
\hline Fast & - & - & $0.90(0.82 \text { to } 0.99)^{\star}$ \\
\hline Slow & - & - & $0.72(0.63 \text { to } 0.84)^{\star \star \star}$ \\
\hline \multicolumn{4}{|c|}{$\begin{array}{l}{ }^{*} \mathrm{p}<0.05,{ }^{* *} \mathrm{p}<0.01,{ }^{* * *} \mathrm{p}<0.001 \text {, adjusted for covariates. } \\
\text { †Surgical history of oesophagus/stomach was also adjusted (data not shown). } \\
\text { †Surgical history of oesophagus/stomach and treatment history of heart disease, kidney disease, live } \\
\text { adjusted (data not shown). } \\
\text { §Treatment history of heart disease was also adjusted (data not shown). } \\
\text { IQ3: Do you walk for at least } 1 \mathrm{~h} \text { every day or have equivalent physical activities in your daily life? } \\
\text { ††Q10: How fast do you eat compared to others? } \\
\text { BMI, body mass index; GPT, glutamic pyruvic transaminase; HbA1c, glycated haemoglobin. }\end{array}$} \\
\hline
\end{tabular}


disease status. After adjustment for covariates, among non-evacuees/temporary-evacuees, no significant associations between diseases risk and radiation levels were observed post-incident for any of the outcomes (data not shown). We conducted sensitivity analyses by constructing models using radiation levels in a categorical form (quantiles), rather than as a continuous variable, and results were similar. These results indicate that level of radiation exposure did not affect disease risk for these chronic diseases. Note that, according to WHO's dose estimation, the annual effective doses in the first year following the incident were $3-5 \mathrm{mSv}$ in the general population of the Fukushima Prefecture, excluding most affected areas (ie, Namie Town and Iitate Village, $30 \mathrm{~km}$ northwest of the plant). These doses are too low to increase the radiation-induced health risks, as mentioned earlier. ${ }^{16}$ Associations of other covariates with the disease risks in this subset of the population were similar to those estimated using the whole study population (data not shown).

\section{DISCUSSION}

Adequate control of diabetes, hyperlipidaemia and hypertension is vital to reduce the risk of developing serious complications, such as heart disease, stroke and kidney failure. In the aftermath of a disaster, and following evacuation, control of these chronic conditions is very challenging as a result of decreased access to medical care due to change of personal doctor or regular clinic/hospital, reduced physical exercise and dietary change at evacuation sites. ${ }^{46}{ }^{47}$ Change in socioeconomic circumstances, such as in income and/or employment, and chronic stress, are also known to have a negative impact on control of chronic health conditions. ${ }^{48}$ In addition, the Fukushima incident posed specific radiation disaster-specific issues. Anxiety about radiation exposure caused a great deal of stress and reduced outdoor activity levels, resulting in reduced physical exercise and reluctance to access medical care. ${ }^{49}$ Avoidance of particular foodstuffs prone to radioactive contamination also led to dietary changes. ${ }^{12}$ For these reasons, in the case of the Fukushima incident, post-incident evacuation and radiation levels might be major underlying factors that affect chronic health control.

In this study we found that, in the 4-year follow-up of individuals in Fukushima Prefecture, there have been significant increases of prevalence of diabetes and hyperlipidaemia both in evacuees and in non-evacuees/ temporary-evacuees, in comparison with baseline years (RR of 1.27-1.60 for diabetes and 1.12-1.30 for hyperlipidaemia). Evacuees had a small but significantly higher risk of hyperlipidaemia than non-evacuees/temporaryevacuees. Despite high levels of public concern, radiation levels were not associated with these disease risks.

Although many previous studies reported postdisaster increases in hypertension prevalence, adequate control of hypertension should be achievable after a disaster, as day-to-day self-blood pressure monitoring is possible using a home blood pressure monitor. ${ }^{50}$ In contrast, diabetes and hyperlipidaemia are more difficult to control after a disaster; almost all available blood glucose and cholesterol monitoring require invasive procedures, selfmonitoring is less accepted by patients, resulting in reduced patient compliance in diabetes and hyperlipidaemia monitoring and treatment. ${ }^{51}$ Previous studies have reported associations between experiences of lifethreatening disaster and reduced chronic health control. ${ }^{41}$ The findings of our study show that, regardless of evacuation, there was significantly increased risk of diabetes and hyperlipidaemia more than 3 years after



Figure 2 Box plots for the distribution of radiation levels at non-evacuees'/temporary-evacuees' residences by disease status. The bar represents the median radiation air dose rate, the box shows the 25th and 75th centiles, whiskers are 1.5 times the IQR, and outliers and extreme outlets are shown by dots and asterisks, respectively. 
the incident. This persistent impact on chronic health indicates the necessity of paying particular attention to the mid-term to long-term effects of a disaster on diabetes and hyperlipidaemia.

The fact that evacuees had higher risk of hyperlipidaemia but no significant difference in diabetes risk than no-evacuees/temporary-evacuees post-incident may reflect public and clinicians' substantial concern about diabetes. This heightened concern over diabetes, even in the post-evacuation environment (characterised by reduced physical exercise, dietary change and reduced access to medical care as well as socioeconomic changes), may have resulted in diabetes risk in evacuees being successfully managed at a similar level as in non-evacuees/temporary-evacuees. This was not the case for hyperlipidaemia, and these findings suggest that all parties involved in local healthcare should pay more attention to hyperlipidaemia control, with a particular focus on evacuees. Here, our intention is not to overemphasise the health risks from evacuation, but to highlight that there is scope for reducing evacuation-related health impacts by strengthening local health system disaster resilience. For instance, promoting disease-specific and target-specific measures at community or population level, and/or healthy lifestyle activities at individual level (eg, weight control, sleep behaviour and balanced diet), which we identified as differing between evacuees and non-evacuees/temporary-evacuees post-incident (see online supplementary table S1).

In our study sites, city offices and municipal hospitals began offering external and internal radiation exposure screening programmes for free to city residents, a few months after the incident, using personal radiation dosimeters and whole-body counting machines. ${ }^{10}$ We found no significant associations between disease risks and radiation levels post-incident for any of the diseases, which may indicate that the public's understanding of the potential radiation risk had been fostered and public anxiety about radiation exposure might not have been strong enough to influence disease risk. In fact, low-risk dietary and lifestyle behaviours were well examined in our study sites. ${ }^{12}$ Although residents' dietary patterns might have been changed immediately following the incident with a potential move to increased meat consumption due to concern over the radiocontamination of soil (vegetables/fruits) and seawater (fishery products), ${ }^{52}$ this change was likely temporary. As of the end of 2013, it was known that all foodstuffs, except for mushrooms and mountain vegetables, were at a low risk of radiation contamination and under no governmental shipment restrictions. ${ }^{12}$

\section{Limitations}

This study has several limitations. First, because the definition of 'evacuees' in this study was those who were living in the districts denoted compulsory evacuation zones, the 'evacuees' did not include voluntary temporary evacuees who were living outside the evacuation zones. Although, in Minamisoma, the proportion of people who were forced to evacuate was about $27 \%$ of the total population, ${ }^{33}$ according to the city office, the population declined to about $10 \%$ right after the incident, indicating that approximately $60 \%$ of people might have voluntarily evacuated. However, because they were temporary evacuations and the population has rebounded to more than $70 \%$ of the pre-incident level so $\mathrm{far}^{53}{ }^{53}$ we assumed that many of the voluntary evacuees returned soon or months/years after the evacuations, though we lack reliable data to evaluate this. Therefore, we are differentiating the effect of mandatory evacuation from non-evacuees/temporary-evacuation. Second, the health check-ups were undertaken on a voluntary basis, and only offered to the self-employed, potentially biasing the results and limiting our ability to generalise to the wider population. Third, the study population comprised only those self-employed and aged 4074 years, and did not consider the late-stage elderly over 75 years. Also, those who evacuated so far from Minamisoma and Soma or adjacent areas that they were not able to take the cities' health check-ups were not included in the study. Satoh $e t a l^{26}$ reported that evacuees had about 1.4 times higher diabetes risk than non-evacuees/temporary-evacuees 1 year after the Fukushima incident, after adjustment for covariates. This finding was contrary to the result of our study, which suggested no significant difference in diabetes risk between evacuees and non-evacuees/temporary-evacuees post-incident. However, it must be noted that the study population the report by Satoh $e t a t^{26}$ included people aged more than 75 years, and up to 90 years (although the authors adjusted for age in their analyses), and some who experienced long-distance evacuations beyond Fukushima Prefecture. Given this, we should bear in mind that evacuation may engender differential vulnerability for elderly people in terms of chronic health conditions, depending on the distance of evacuation. Fourth, it should be noted that evacuation sites include several housing styles, such as shelters, temporary housing, neighbours'/relatives' house, or new houses. As of July 2015, according to the official website of Minamisoma City, among the evacuees, 30\% were staying at neighbours'/relatives' houses, $34 \%$ were living in temporary housing and the remaining $36 \%$ had obtained their own new houses. ${ }^{53}$ However, we were not able to consider these differences in evacuation experience in our analysis. Because different housing situations may create social stratification, which, in turn, engender differential exposure to post-evacuation health-compromising conditions, further investigation is necessary to clarify those housing styles that are more relevant to chronic health issues. Finally, our study sites suffered not only from the Fukushima nuclear incident, but also the tsunami that ravaged the seacoast areas of the cities right before the incident. Although the dataset of Soma did not include the data of tsunami victims, that of Minamisoma contained tsunami victims' data 
because of the different data set management/processing by the city offices. Since it was impossible to identify the tsunami victims of Minamisoma in the data set collected, our study was not able to adjust for the health impacts of the tsunami. However, given that the percentage of the tsunami victims in the total population of Minamisoma was only $1 \% \quad(n=790$, including missing persons), ${ }^{54}$ the statistical influence of this limitation on the analysis results is likely to be very small or marginal.

\section{CONCLUSIONS}

The singularity of this study is that the evacuation following the Fukushima incident was found to be statistically significantly associated with a small increased risk of hyperlipidaemia in the long term (ie, years) among people aged 40-74 years. No evacuation effect on diabetes or hypertension was observed, however, diabetes risk was increased in the whole study population (evacuees and non-evacuees) 2-3 years post-incident. Our findings could be used to guide actions taken before and during disaster events where mass evacuation takes place in order to manage the postdisaster evacuationrelated health risks.

\section{Author affiliations \\ ${ }^{1}$ Department of Epidemiology and Biostatistics, School of Public Health, Imperial College London, London, UK \\ ${ }^{2}$ MRC-PHE Centre for Environment and Health, Department of Epidemiology and Biostatistics, School of Public Health, Imperial College London, London, UK ${ }^{3}$ Division of Social Communication System for Advanced Clinical Research, The Institute of Medical Science, University of Tokyo, Tokyo, Japan \\ ${ }^{4}$ Department of Surgery, Minamisoma Municipal General Hospital, Fukushima, Japan \\ ${ }^{5}$ Department of Internal Medicine, Soma Central Hospital, Fukushima, Japan}

Acknowledgements The authors express their gratitude to the Minamisoma and Soma city employees and Minamisoma Municipal General Hospital staff for data collection and management. Without their involvement, our study could not have reached its present form.

Contributors All the authors conceived and designed the study, and take responsibility for the integrity of the data and the accuracy of the data analysis. SN, MT and AO acquired the data. SN, MB, MT, AO, TM and SH analysed and interpreted the data. SN, MB and SH conducted statistical analysis and drafted the article. All the authors made critical revision of the manuscript for important intellectual content and gave final approval for the manuscript.

Funding This study was supported by a scholarship from Japan Student Services Organization.

\section{Competing interests None declared.}

Ethics approval Ethical approval for the study was granted by the ethics committee of the Institute of Medical Science, University of Tokyo, Japan, authorisation number 25-40-1011.

Provenance and peer review Not commissioned; externally peer reviewed.

Data sharing statement No additional data are available.

Open Access This is an Open Access article distributed in accordance with the Creative Commons Attribution Non Commercial (CC BY-NC 4.0) license, which permits others to distribute, remix, adapt, build upon this work noncommercially, and license their derivative works on different terms, provided the original work is properly cited and the use is non-commercial. See: http:// creativecommons.org/licenses/by-nc/4.0/

\section{REFERENCES}

1. Brumfiel G, Cyranoski D. Quake sparks nuclear crisis. Nature 2011;471:273-5.

2. Priest ND. Radiation doses received by adult Japanese populations living outside Fukushima Prefecture during March 2011, following the Fukushima 1 nuclear power plant failures. J Environ Radioact 2012;114:162-70.

3. Imanaka T, Endo S, Sugai M, et al. Early radiation survey of litate village, which was heavily contaminated by the Fukushima Daiichi accident, conducted on 28 and 29 March 2011. Health Phys 2012;102:680-6.

4. Kamada N, Saito O, Endo S, et al. Radiation doses among residents living $37 \mathrm{~km}$ northwest of the Fukushima Dai-ichi Nuclear Power Plant. J Environ Radioact 2012;110:84-9.

5. Yoshida-Ohuchi H, Hirasawa N, Kobayashi I, et al. Evaluation of personal dose equivalent using optically stimulated luminescent dosemeters in Marumori after the Fukushima nuclear accident. Radiat Prot Dosimetry 2013;154:385-90.

6. Hayano RS, Tsubokura M, Miyazaki M, et al. Internal radiocesium contamination of adults and children in Fukushima 7 to 20 months after the Fukushima NPP accident as measured by extensive whole-body-counter surveys. Proc Jpn Acad Ser B Phys Biol Sci 2013;89:157-63.

7. Hayano RS, Tsubokura M, Miyazaki M, et al. Comprehensive whole-body counter surveys of Miharu-town school children for three consecutive years after the Fukushima NPP accident. Proc Jpn Acad Ser B Phys Biol Sci 2014;90:211-13.

8. Hayano RS, Tsubokura M, Miyazaki M, et al. Whole-body counter surveys of Miharu-town school children for four consecutive years after the Fukushima NPP accident. Proc Jpn Acad Ser B Phys Biol Sci 2015;91:92-8.

9. Tsubokura M, Gilmour S, Takahashi K, et al. Internal radiation exposure after the Fukushima nuclear power plant disaster. JAMA 2012;308:669-70.

10. Tsubokura M, Kato S, Morita T, et al. Assessment of the Annual Additional Effective Doses amongst Minamisoma Children during the Second Year after the Fukushima Daiichi Nuclear Power Plant Disaster. PLoS ONE 2015;10:e0129114.

11. Tsubokura $\mathrm{M}$, Kato $\mathrm{S}$, Nihei $\mathrm{M}$, et al. Limited internal radiation exposure associated with resettlements to a radiation-contaminated homeland after the Fukushima Daiichi nuclear disaster. PLOS ONE 2013;8:e81909.

12. Tsubokura M, Kato S, Nomura S, et al. Reduction of high levels of internal radio-contamination by dietary intervention in residents of areas affected by the Fukushima Daiichi nuclear plant disaster: a case series. PLOS ONE 2014;9:e100302.

13. Tsubokura $M$, Kato $S$, Nomura $S$, et al. Absence of internal radiation contamination by radioactive cesium among children affected by the Fukushima Daiichi nuclear power plant disaster. Health Phys 2015:108:39-43.

14. Tsubokura M, Nihei M, Sato K, et al. Measurement of internal radiation exposure among decontamination workers in villages near the crippled Fukushima Daiichi Nuclear Power Plant. Health Phys 2013;105:379-81.

15. Tsubokura M, Shibuya $\mathrm{K}$, Kato $\mathrm{S}$, et al. Acute intake of radionuclides immediately after the incident as the main contributor of the internal radiation exposure after Fukushima Daiichi nuclear disaster. JAMA Pediatr 2013;167:1169-70.

16. World Health Organization. Health risk assessment from the nuclear accident after the 2011 Great East Japan earthquake and tsunami, based on a preliminary dose estimation. Geneva: World Health Organization, 2013.

17. United Nations Scientific Committee on the Effects of Atomic Radiation. Annex A: levels and effects of radiation exposure due to the nuclear accident after the 2011 great east-Japan earthquake and tsunami. New York: United Nations Scientific Committee on the Effects of Atomic Radiation, 2014.

18. Burton LC, Skinner EA, Uscher-Pines L, et al. Health of Medicare Advantage plan enrollees at 1 year after Hurricane Katrina. Am J Manag Care 2009;15:13-22.

19. Dosa D, Hyer K, Thomas K, et al. To evacuate or shelter in place: implications of universal hurricane evacuation policies on nursing home residents. J Am Med Dir Assoc 2012;13: 190.e1-7.

20. Kario K, Ohashi T. Increased coronary heart disease mortality after the Hanshin-Awaji earthquake among the older community on Awaji Island. Tsuna Medical Association. J Am Geriatr Soc 1997;45:610-13.

21. Sofia S, Melone A, Manzoli L, et al. Cardiovascular and cerebrovascular events pre- and post-earthquake of 6 April 2009: the Abruzzo's experience. Am J Hypertens 2012;25:556-60. 
22. Nuclear Regulation Authority. Conceptual diagram of evacuation-directed zones and the number of population and households of each region (as of the end of December 2013). 2013. http://www.meti.go.jp/earthquake/nuclear/pdf/131231a.pdf (accessed 5 Nov 2015).

23. Nuclear Regulation Authority. Conceptual diagram of evacuation-directed zones and the number of population and households of each region (as of 5 September 2015). 2015. http:// www.meti.go.jp/earthquake/nuclear/kinkyu/hinanshiji/2015/pdf/0905 02gainenzu.pdf (accessed 6 Nov 2015)

24. Yasumura S, Goto A, Yamazaki S, et al. Excess mortality among relocated institutionalized elderly after the Fukushima nuclear disaster. Public Health 2013;127:186-8.

25. Nomura S, Gilmour S, Tsubokura M, et al. Mortality risk amongst nursing home residents evacuated after the Fukushima nuclear accident: a retrospective cohort study. PLOS ONE 2013;8:e60192.

26. Satoh $H$, Ohira $T$, Hosoya $M$, et al. Evacuation after the Fukushima Daiichi Nuclear Power Plant Accident is a cause of diabetes: results from the Fukushima Health Management Survey. J Diabetes Res 2015;2015:627390.

27. Tsubokura M, Takita M, Matsumura T, et al. Changes in metabolic profiles after the Great East Japan Earthquake: a retrospective observational study. BMC Public Health 2013;13:267.

28. Yabe H, Suzuki Y, Mashiko H, et al. Psychological distress after the Great East Japan Earthquake and Fukushima Daiichi Nuclear Power Plant accident: results of a mental health and lifestyle survey through the Fukushima Health Management Survey in FY2011 and FY2012. Fukushima J Med Sci 2014;60:57-67.

29. Cabinet Office of United Kingdom. Evacuation and shelter guidance: non-statutory guidance to complement emergency preparedness and emergency response and recovery. Cabinet Office

(Management \& Personnel Office), 2014.

30. The National Diet of Japan Fukushima Nuclear Accident Independent Investigation Commission. Overview of the damage and how it spread. The official report of the Fukushima nuclear accident independent investigation commission. Tokyo: NAIIC, 2012:29.

31. Twisk JWR. Applied longitudinal data analysis for epidemiology: a practical guide. Cambridge University Press, 2013.

32. Silman AJ, Macfarlane GJ. Epidemiological studies: a practical guide. Cambridge University Press, 2002.

33. Minamisoma City Office. Population based on basic resident register of Minamisoma City. http://www.city.minamisoma.lg.jp/index.cfm/ 8,4705,44,html (accessed 20 Sep 2015).

34. Soma City Office. Population based on basic resident register of Soma City. http://www.city.soma.fukushima.jp/data/new/jinkou/j_ jinkou_setai.html (accessed 20 Sep 2015).

35. Japan Atherosclerosis Society. Guidelines for diagnosis and prevention of atherosclerotic cardiovascular diseases. Tokyo, 2007.

36. World Health Organization. Use of glycated haemoglobin (HbA1C) in the diagnosis of diabetes mellitus: abbreviated report of a WHO consultation. Geneva, 2011.

37. James PA, Oparil S, Carter BL, et al. Evidence-based guideline for the management of high blood pressure in adults: report from the panel members appointed to the Eighth Joint National Committee (JNC 8). JAMA 2014;311:507-20.

38. International Commission on Radiological Protection. ICRP publication 103: recommendations of the ICRP. New York, 2013.

39. Ministry of Education, Culture, Sports, Science and Technology. Results of airborne monitoring survey. http://radioactivity.nsr.go.jp/ja/ list/362/list-1.html (accessed 22 Jun 2015).

40. Hanson CL, Henggeler SW, Burghen GA. Model of associations between psychosocial variables and health-outcome measures of adolescents with IDDM. Diabetes Care 1987;10:752-8.

41. Inui A, Kitaoka $\mathrm{H}$, Majima M, et al. Effect of the Kobe earthquake on stress and glycemic control in patients with diabetes mellitus. Arch Intern Med 1998;158:274-8.

42. McCuen RH. Modeling hydrologic change: statistical methods. Florida: Lewis Publishers, 2003.

43. Barlassina C, Lanzani C, Manunta $P$, et al. Genetics of essential hypertension: from families to genes. J Am Soc Nephrol 2002;13 (Suppl 3):S155-64.

44. Goldberg AC, Hopkins PN, Toth PP, et al. Familial hypercholesterolemia: screening, diagnosis and management of pediatric and adult patients: clinical guidance from the National Lipid Association Expert Panel on Familial Hypercholesterolemia. J Clin Lipidol 2011:5:133-40.

45. Harrison TA, Hindorff LA, Kim H, et al. Family history of diabetes as a potential public health tool. Am J Prev Med 2003;24:152-9.

46. Jhung MA, Shehab N, Rohr-Allegrini C, et al. Chronic disease and disasters medication demands of Hurricane Katrina evacuees. Am J Prev Med 2007;33:207-10.

47. Miller AC, Arquilla B. Chronic diseases and natural hazards: impact of disasters on diabetic, renal, and cardiac patients. Prehosp Disaster Med 2008;23:185-94.

48. Solar O, Irwin A. A conceptual framework for action on the social determinants of health. Social Determinants of Health Discussion Paper 2 (Policy and Practice). Geneva: World Health Organization, 2010.

49. Sugimoto A, Krull S, Nomura S, et al. The voice of the most vulnerable: lessons from the nuclear crisis in Fukushima, Japan. Bull World Health Organ 2012;90:629-30.

50. Kario K. Disaster hypertension-its characteristics, mechanism, and management. Circ J 2012;76:553-62.

51. Frontino $G$, Meschi $F$, Bonfanti $R$, et al. Future perspectives in glucose monitoring sensors. European Endocrinology 2013;9:21-6.

52. Nishikawa $Y$, Fukuda $Y$, Tsubokura M, et al. Managing type 2 diabetes mellitus through periodical hospital visits in the aftermath of the Great East Japan Earthquake Disaster: a retrospective case series. PLoS ONE 2015;10:e0125632.

53. Minamisoma City Office. Evacuation and living situation. https:// http://www.city.minamisoma.lg.jp/index.cfm/10,853,58,html (accessed 20 Sep 2015)

54. Kaji H, Izumi J, Yamamoto K. Reconstruction from the great east Japan earthquak and nuclear accident. Tokyo: Gihodo shuppn, 2012. 